\title{
Re- Enforcing Factors Related to Consumption of Alcoholic Beverages amongst High School Students in the North Central Province, Liberia
}

\author{
${ }^{1}$ Joseph Nyan Gono* and ${ }^{2}$ Prof. Dora O. Akinboye, PhD \\ ${ }^{1} \mathrm{PhD}$ Candidate in Public Health, Babcock University, Ogun State, Nigeria \\ ${ }^{2}$ Dean, College of Allied and Public Health, Babcock University, Nigeria \\ *Corresponding Mail: nyankonah@gmail.com
}

\begin{abstract}
This study endeavored to establish trends in the re-enforcing factor related to the consumption of alcoholic beverages among high school students in Liberia, using an experimental research design. A sample of 440 students from two selected schools was determined using Cochran's formula. A sixteen item questionnaire with a reliability coefficient of 0.70 was administered to the 440 students to identify those who drink alcohol. Applying $G$ Power formula, 84 students were randomly selected out of the 170 students who drink alcohol as participants. Another validated questionnaire with a reliability coefficient of 0.76 was used to collect data from the field. Descriptive statistics and $t$-test were used to analyze the data. The study concludes that the use of the Alcohol and Life Skills Training Model, which was employed to the experimental group is an effective educational tool to prepare students to make responsible decision about abstaining from drinking alcoholic beverages than the HIV/ AIDS Model which was employed to the control group. It is therefore recommended that the Government of Liberia should adopt the Alcohol and Life Skills Training Model into the National High School Curriculum in order to prevent and control the consumption of alcohol by students in high schools. Secondly, researchers and the Ministry of Education in conjunction with other Ministries such as Health and Youth should conduct further research on a wider scale on alcohol consumption among the youth, including the in-school and the out of school adolescents in Liberia.
\end{abstract}

Key words: Alcohol, consumption, Health education, Life Skills Training, High School, students, Public health

\section{Introduction}

The use of psychoactive substance including alcohol by mankind dates back to many years ago. In his argument, Room (2015) pointed out that these substances were in use in different parts of the world before the arrival of Europeans during their expedition into the world; however the substance was produced on a low scale for consumption by leaders of the communities who controlled and restricted the usage. Such usage was not intended for commercial purpose but was later commercialized with the arrival of the Europeans in the countries. Realizing the vices associated with the large production and consumption of substances, several attempts made to control the usage globally proved futile for alcohol and tobacco; the strategies of coercion was then changed to persuasion, which then left the two commodities without a universally accepted stringent method of control.
Reports of previous researches (Hormenu, Hagan, \& Schack, 2018) indicated evidences that alcohol consumption among adolescents has become a general societal problem and is on the increase trend, especially in developing countries like Ghana. Alcohol consumption among adolescents or youth is a serious health and social problem, which affects not only the individuals involved, but the relations with other people and the society as well. Alcohol is a psychoactive and depressant agent that is being commonly abused by the youth for several personal reasons in Liberia. It is this substance that is found in beer, wine or whiskey that can make a person drunk. The effects of this substance on the various neural pathways and parts of the brain depends on the dose ingested, genetic factors and the learned experience of the drinker as well as the aspects of the settings (WHO, 2018). What distinguishes 
alcohol from other addictive substances is that in addition to being accepted universally as a legal substance, and in spite of the vices associated with the use of alcohol, many African countries have not adapted any policy at the national level to control or reduce its use (Armiya'u, 2015).

The period of transition known as adolescence in the life of the youthful population, which includes high school students, is recognized as a critical period in the development of lifestyle practices such as alcohol drinking behavior. During this period, the pattern of alcohol use advances from testing to more progressive patterns in adolescence and young adulthood. The use of alcohol is associated with mortality, accidents and injuries. Exposure to alcohol also impedes normal social, psychological and physiological development during this period of development (Verho, Laatikainen, Vartiainen, \& Puska (2012). Alcohol seems to be the most abused substance among the youth in Liberia, especially among students with a prevalence of $51 \%$ and the mean age of $19 \pm 3$ years; the consumption of alcohol exposed the youth leads to unwholesome practices of high-risk behaviors such as engagement into abuse of other substances (Harris, Levey, Borba, Gray, Carney, \& Hendersen, 2011).

Liberia was engaged into a fierce civil war which lasted for fourteen years during which educational facilities were destroyed, leading to the closure of schools and consequently leaving the students to either enroll voluntarily or be conscripted into one of the fighting groups in the country. The population of Liberia, at the time of this study, was reported to be over four million, of which sixty-five percent consisted of the youthful population. Alcohol seemed to be the most commonly tried substance with close to half of all the youthful respondents in a study admitting consuming it at least once in their lives (Quiterio, Harris, Borba, \& Henderson, 2013).

Previous studies alluded to the fact that alcohol and other illicit substances were used by war affected populations, especially of low socio- economic class in refugee or displaced camps around the world, in order to deal with some mental problems associated with war such as depression, anxiety and stress disorders. The prevalence rate of alcohol use of 50\% among secondary school students in Liberia was reported as being higher than Kenya which had a prevalence rate of $5.2 \%$. This rate could be mainly due to factors such as a means to cope with psychological impact from the Liberian civil conflict that lasted for 14 years (Quiterio et al, 2013).

Previous studies have reported that globally, there was more than $26.5 \%$ of all 15 - 19 year-olds who were drinkers of alcohol, which amounted to 155 million adolescents. In addition, 64.2 million had already consumed alcohol but ceased to drink in the past 12 months (WHO, 2018). Easy access to alcohol in the community was implicated as a significant contributor to alcohol consumption and abuse by the youth, especially among the age group of $20-$ 25 years, which made it a serious public health challenge in Ghana. The prevalence rate of alcohol use was forty-three percent, with other factors associated with the consumption of alcohol among the youth in the study being advertisement and peer pressure (Osei-Bonsu, Appiah, Norman, Asalu, Kweku, Ahiabor, \& Boadu., 2017).

Alcohol was and is still an abused substance among the youth in Liberia and had the prevalence of $51 \%$ with a mean age range of $19 \pm 3$ years (Harris et al., 2011). Alcohol was commonly tried substance amongst the youth with close to half of all respondents consuming it at least once in their lives (Quiterio, Harris, Borba, \& Henderson, 2013). Easy access to alcohol in the community, had contributed significantly to the consumption and abuse of the substance by the youth, especially of the age group of 20 - 25 years, with a prevalence of $43 \%$ in Ghana (Osei-Bonsu et al., 2017). With the paucity of literature on the use of alcohol among high school students in Liberia, studies from the neighboring countries were considered. The prevalence of alcohol consumption among teenagers in Nigeria, especially those at secondary school level has led to a number of problems such as decline in students' academic performance, violence and various forms of anti-social behaviors (Bada, \& Adebiyi, 2014). Room (2015) pointed out that "in the wake of the repeal of alcohol prohibition, alcohol and tobacco were renormalized and conceived quite separately from 'narcotic drugs', a separation that lasted for most of the $20^{\text {th }}$ century. As alcohol prohibition lost its appeal, the alternative put forward was 'alcohol control' - what today would be termed 'harm reduction.' The main exception to the trend was the campaigns against drunk-driving, in which Australia has been in the forefront in taking effective action.

A study conducted by Mohammed and Khaton (2017) concluded following the PRECEDE-PROCEED Model is an effective method in planning for and 
providing health education to improve knowledge, attitudes and behaviors regarding drug abuse and addiction among adolescent students and promoting enabling and reinforcing factors that support prevention of such problem. Following this advice, this study focused on educational intervention on the re- enforcing factors related to consumption of alcoholic beverages amongst High School students in Liberia. The study was guided by the following two research questions: (1) what is the perception of students in the control and the experimental group on various aspects of the reinforcing factor toward alcohol drinking? (2) Is there is a significant difference in mean scores on the reinforcing factors between the control and experimental groups in the post intervention and follow session?

\section{Related Literature and Studies}

This section presents the review of literatures from previous studies related to the main constructs of the study.

\section{Trend in Alcohol Consumption}

The consumption of alcohol was practiced in many cultures around the world for socialization. Despite the health problems associated with the consumption, the practice was considered as societal norm, and therefore embraced by those societies (WHO, 2018). Recently, consumption of alcohol by underage adolescents was a major public health problem confronting many high, middle and low income countries globally (Alex-Hart, Opara, \& Okagua, 2015).The same study pointed out that in 2010, the World Health Organization's Regional Report on alcohol showed that the proportion of adolescents in the age of 15 to 19 years drinking alcohol was $34.1 \%$ globally and $69.5 \%, 52.7 \%$, 37.3\% and $29.3 \%$ in Europe, America, Western Pacific Region and Africa, respectively. Osei-Bonsu et al. (2017) indicated that in a five year worldwide survey, the trend of alcohol consumption among young people between the ages of $18-25$ was assessed in 82 countries and it was revealed that there was $80 \%$ increase in consumption, $11 \%$ decrease in consumption and $6 \%$ stable consumption among respondents.

According to Dumbili (2013), the consumption of alcohol by Africans, especially Nigerians was not strange, but was intended for special rituals and ceremonial activities that only men were allowed to be partaker of. Women and children or youth were prohibited from taking part in those rituals that required drinking alcohol. In addition, the author pointed out that prior to the coming of the Europeans to Africa, alcohol was used but on a low scale for purposes such as marriage and festivities connected with enthronement and never for commercial purpose. The decrease of the prevalence of cannabis in Europe and the slight increase in the use in Africa in the past decade has probably rendered the continent vulnerable by the production of some illicit drugs using it as a trade route for these substances to other parts of the world. This has exposed Africa to many vices including drug use and abuse, crime and health and development related challenges (Armiya'u, 2015).

\section{Alcohol Use Trend in Liberia}

Alcohol per capita consumption was categorized into recorded and unrecorded, with Liberia's recorded per capita consumption being reported at 3.0 while the unrecorded was at 1.5 , totaling 4.5 . The per capita alcohol consumption for men was 17.1 while for women was 14.9 (Ferreira, Borges, Rehm, Dias, Babor, \& Parry, 2016). As a result, alcohol use has health and social consequences for those who drink, those around them and the nation as a whole. Alcohol-related deaths result from such diseases as cancer, cirrhosis of the liver, pancreatitis, motor vehicle accidents, falls, drowning, suicide and homicide. Also it is indicated that by 2016, the recorded alcohol per capita (15+) consumption (in liters of pure alcohol) by type of alcoholic beverage in Liberia was as follow (WHO, 2018): Spirit accounted for 88\%, while beer accounted for $9 \%$, followed by wine, $2 \%$ and others $1 \%$. However, there are two groups of wine which include imported and the locally produced wine from palm and piassava trees. It is not clear whether the locally produced wine was inclusive in the report.

WHO (2018) further indicated that though Liberia had a National legal minimum age for off-premise sales of alcoholic beverages (beer/wine/spirits), there was no written policy (adopted/ revised National Action Plan), no legally binding regulations on alcohol advertising/product placement, no legally required health warning labels on alcohol advertisements/containers and no monitoring system. These trends indicate a gap for researchers to address.

\section{Reasons for alcohol Consumption}

Parental alcohol problems appear to co-exist with an anti- social pattern of alcohol consumption in 
adolescents that involves drinking alone and drinking to feel intoxicated or to forget about problems. The external, social motives to drink, which were shared by most adolescents, nearly one in five of the adolescents studied reported salient internal motives to drink that tended to coexist with alcohol problems in their parents (Chalder, Elgar \& Bennett, 2006). Majority of the students, who drank alcohol, did it to experiment, to feel what it was like, just to have good time with friends and to be able to sleep. Some respondents reported drinking because they were already addicted to alcohol. It is also reported that some of the students who were addicted to alcohol belonged to the 16 to 20 age groups (Alex-Hart, Opara, \& Okagua, (2014).

\section{Impact of Alcohol Consumption}

The health and social harms from drinking alcohol occur through three main mechanisms: 1) the toxic effects of alcohol on different organs and tissues in the victim's body (resulting, for instance, in liver disease, heart disease or cancer); 2) development of alcohol dependence whereby the drinker's selfcontrol over his or her drinking is impaired, often involving alcohol-induced mental disorders such as depression or psychoses; and 3) intoxication - the psychoactive effects of alcohol in the hours after drinking (WHO, 2018).

Substance use continues to be a major risk behavior among youth, with consequent physical and/or mental health complications (Oshodi, Aina, \& Onajole, 2010). Alcohol use in the adolescents is associated with alterations in verbal learning, visual-spatial processing, memory and attention as well as with deficits in development and integrity of grey and white matter of the central nervous system. These neurocognitive alterations by adolescents' alcohol use seem to be related to behavioral, emotional, social and academic problems in later life (WHO, 2018).

Globally, alcohol is responsible for $3.2 \%$ of all deaths annually and $5 \%$ of deaths in people between the ages of 5 and 29 years. Many of these deaths resulted from injuries caused by heavy drinking. Starting to drink at an early age has also been associated with alcohol dependence during adult life, unintentional injuries such as those that result from falling down, burns and drowning and with increased tendencies towards involvement in careless sex (Alex-Hart, Opara, \& Okagua, (2014). In recent years, public attention both in Australia and globally has been turning back to alcohol problems, as it has been gradually realized that the health and social problems from drinking are far greater than from illicit drugs. But policy changes which respond to this realization have proved difficult, on the one hand because of the difficulty of changing the international drug treaties and the resistance of the drug prohibition establishment, and on the other hand, the centrality of alcohol in many western cultures and the economic interests involved in the alcohol market (Room, 2015). The weight of new evidence, especially of alcohol's role in the incidence and course of HIV/AIDS was particularly relevant to African countries and pointed to the need for a strong policy response to reduce the alcohol related burden of the disease (Ferreira, Borges, Rehm, Dias, Babor, \& Parry, 2016).

Alcohol consumption can suppress the immune system, which is documented in individuals with heavy alcohol exposure, which increases the risk for active tuberculosis. The risk rises with the increase in levels of alcohol consumption. There is a threefold increase in the risk of tuberculosis associated with a diagnosis of alcohol use disorder. Consumption can influence the absorption and metabolism of tuberculosis drugs and increase the risk of chemically-driven liver damage, which is already a common side effect of tuberculosis medications. People with alcohol use disorders are at greater risk for poor treatment (WHO, 2018).

Hoque and Ghuman (2012) indicates that parents' negative behaving patterns in relation to drinking alcohol has a strong negative influence on the children's decision to engage in drinking liquor in the future. The study also pointed out that there is an association between parents' drinking habit and the children's alcohol use, because children tend to imitate their parents. In support of the argument Singh and Niwas (2017) also concur that parents can influence children's future use of liquor.

\section{Research Methodology}

This section dealt with the method utilized to conduct the study. It highlighted on such areas like the research design, population and sampling, data collection procedures and ethical considerations.

\section{Research Design}

This study employed an experimental research design, using the quantitative method. The experimental design is one which uses two main groups namely control and experimental in order to come up with relevant findings using the intervention approach.

\section{East African Journal of Education and Social Sciences (EAJESS) 1(2)11-19}




\section{Population and Sampling}

This study was conducted in the North Central province of Liberia which was randomly selected out of four provinces in the country. Random sampling method was also used to select two out of three counties in the province as well as the control and the experimental counties from which the researchers randomly picked a participating school, one being the experimental group while the other being the control group. The researchers distributed a questionnaire to a sample of 440 out of 5,500 Grade 7, Grade 8, Grade 10 and Grade 11 students in the two schools using Cochran's formula. A sixteen item validated questionnaire with a reliability coefficient of 0.70 was administered to the 440 students to identify those who drink alcohol. Applying the $\mathrm{G}$ Power formula, 84 students were randomly selected out of the 170 students who drink alcohol as participants.

\section{Data collection procedures}

The sessions for the training of the participants in the experimental and the control groups took one hour a week for a period of eight weeks. The participants in the experimental group were instructed through a module drawn from the use of alcohol and life skills training while those in the control group received the instruction from the module developed from HIV/AIDS (placebo). Prior to the beginning of the study, a questionnaire was administered to the participants in both groups which constituted the baseline information. At the end of week 8 and 12, the same instrument was administered to the same participants to form the immediate post intervention and follow up information respectively.

\section{Ethical consideration}

Ethical clearances were obtained from the Babcock University Health Research Ethics Committee (BUHREC) in Nigeria and the University of Liberia Pacific Institute for Research and Evaluation Institutional Review Board (UL-PIRE IRB) in Liberia. The informed consents were signed by all participating students before data collection was implemented.

\section{Results and Discussion}

This part presents the analysis of data and findings of the study which was guided by the following research questions: (1) what is the perception of students in the control and the experimental group on various aspects of the reinforcing factor toward alcohol drinking? (2) Is there is a significant difference in mean scores on the reinforcing factors between the control and experimental groups in the post intervention and follow session?

\section{Demographic Characteristics of Respondents}

Table1 presents the demographic distribution of the respondents. The table shows that in line with age distribution, $40(47.6 \%)$ of the respondents were within the ages of $15-19$ years, $39(46.4 \%)$ were within the ages of 20-24 years and $5(6 \%)$ were within the ages of 25-28years.

Table1: Demographic Characteristics

\begin{tabular}{llll}
\hline Variable & Category N=84 & f & \% \\
\hline Age & $15-19$ & 40 & 47.6 \\
& $20-24$ & 39 & 46.4 \\
Gender & $25-28$ & 5 & 6.0 \\
& Male & 58 & 69.0 \\
Educational & Female & 26 & 31.0 \\
Level & Grade 7 8 & 12 & 14.3 \\
& Grade 10 & 19 & 22.6 \\
\multirow{4}{*}{ Residence } & Grade 11 & 29 & 34.5 \\
& Rural & 24 & 28.6 \\
Father's & Urban & 26 & 31.0 \\
occupation & Working for self & 58 & 69.0 \\
& Working for others & 26 & 39.3 \\
Mother's & Not working & 25 & 29.8 \\
occupation & Working for self & 38 & 45.2 \\
& Working for others & 14 & 16.7 \\
& Not working & 32 & 38.1 \\
\hline
\end{tabular}

Most of respondents were between 15- 19 years. Genderwise, $58(69 \%)$ of the respondents were males, while $26(31 \%)$ were females. Hence most of the respondents were males. Concerning the educational level, $12(14.3 \%)$ were in grade 7,19 $(22.6 \%)$ were in grade $8,29(34.5 \%)$ were in grade 10 while $24(28.6 \%)$ were in grade 11 . Thus, most of respondents were in Grade 10.

According to residence distribution, 26 (31\%) of the respondents were living in rural areas while $58(69 \%)$ lived in the urban areas. Hence, majority of the respondents were living in the urban area. As the study related to the occupation of parents, the table shows that $33(39.3 \%)$ of the respondents' fathers were self-employed, 26(31\%) were working with others while $25(29.8 \%)$ were not working. This shows that majority of the respondents' fathers were self-employed. The mother's occupation distribution further shows that $38(45.2 \%)$ of the respondents' mothers were self-employed, $14(16.7 \%)$ were working for others while $32(38.1 \%)$ were not working. 


\section{Descriptive Analysis of Data}

The descriptive statistical tool, in terms of percentage was used to indicate response of the experimental and control groups on the reinforcing factors related to consumption of alcoholic beverage as guided by the first research question.

RQ 1: What is the perception of students in the control and experimental group on various aspects of the reinforcing factor toward alcohol drinking?
The first item in table 2 was related to parents encouraging their children to drink liquor. This was necessary since previous studies revealed that parental alcohol problems appear to influence antisocial pattern of alcohol consumption. Particularly, the external, social motives to drink, which were shared by most adolescents, nearly one in five of the adolescents studied reported salient internal motives to drink that tended to coexist with alcohol problems in their parents (Chalder, Elgar \& Bennett, 2006.

Table 2: Re-enforcing Factors between the Control and the Experimental Groups

\begin{tabular}{|c|c|c|c|c|c|c|}
\hline SN & Statements & Session & Group & Agree & Disagree & Neutral \\
\hline \multirow[t]{6}{*}{1} & \multirow[t]{6}{*}{ Parents should give liquor to children } & \multirow[t]{2}{*}{ Pre } & Control & $2(5.1)$ & $36(92.4)$ & $1(2.6)$ \\
\hline & & & Experiment & $4(10.3)$ & $31(79.5)$ & $4(10.3)$ \\
\hline & & \multirow[t]{2}{*}{ Post } & Control & \multirow[t]{2}{*}{$12(30.7)$} & $23(59)$ & $1(2.6)$ \\
\hline & & & Experiment & & $38(100)$ & - \\
\hline & & \multirow[t]{2}{*}{ Follow Up } & Control & \multirow[t]{2}{*}{$3(10.9)$} & $41(89.2)$ & - \\
\hline & & & Experiment & & $30(100)$ & - \\
\hline \multirow[t]{6}{*}{2} & \multirow[t]{6}{*}{ Parent(s) should drink alcohol at home } & \multirow[t]{2}{*}{ Pre } & Control & $5(12.8)$ & $33(84.6)$ & $1(2.1)$ \\
\hline & & & Experiment & $4(10.3)$ & $33(86.4)$ & $2(5.10$ \\
\hline & & \multirow[t]{2}{*}{ Post } & Control & $11(28.2)$ & 23(58.9) & $2(5.1)$ \\
\hline & & & Experiment & $13(36.1)$ & $23(63.9)$ & - \\
\hline & & \multirow[t]{2}{*}{ Follow Up } & Control & $5(12.8)$ & $34(87.2)$ & - \\
\hline & & & Experiment & - & $38(100)$ & - \\
\hline \multirow[t]{6}{*}{3} & \multirow{6}{*}{$\begin{array}{l}\text { Teachers should send students to buy } \\
\text { liquor. }\end{array}$} & \multirow[t]{2}{*}{ Pre } & Control & $2(5.1)$ & $37(94.9)$ & - \\
\hline & & & Experiment & $3(7.7)$ & $34(87.1)$ & $2(5.1)$ \\
\hline & & \multirow[t]{2}{*}{ Post } & Control & $6(15.4)$ & $30(76.9)$ & $1(2.6)$ \\
\hline & & & Experiment & - & $38(100)$ & - \\
\hline & & \multirow[t]{2}{*}{ Follow Up } & Control & $2(5.2)$ & $37(94.8)$ & - \\
\hline & & & Experiment & - & $38(100)$ & - \\
\hline \multirow[t]{7}{*}{4} & \multirow{7}{*}{$\begin{array}{l}\text { Other siblings should be allowed to } \\
\text { drink liquor. }\end{array}$} & \multirow[t]{2}{*}{ Pre } & Control & $2(5.1)$ & $32(82.1)$ & $5(12.8)$ \\
\hline & & & Experiment & $3(7.7)+$ & $33(84.7)$ & $3(7.7)$ \\
\hline & & \multirow[t]{2}{*}{ Post } & Control & $9(23.1)$ & $26(66.6)$ & $2(5.1)$ \\
\hline & & & Experiment & $2(5.6)$ & $34(94.4)$ & - \\
\hline & & \multirow[t]{3}{*}{ Follow Up } & Control & $5(13)$ & $34(87.2)$ & - \\
\hline & & & Experiment & $5(13.1)$ & $22(57.9)$ & $11(28.9)$ \\
\hline & & & Experiment & $3(7.9)$ & $2(5.2)$ & $33(86.8)$ \\
\hline \multirow[t]{6}{*}{5} & \multirow[t]{6}{*}{ Students bring liquor to school. } & \multirow[t]{2}{*}{ Pre } & Control & $9(23.1)$ & 28(71.7) & $2(5.1)$ \\
\hline & & & Experiment & $17(43.6)$ & $21(53.3)$ & $1(2.6)$ \\
\hline & & \multirow[t]{2}{*}{ Post } & Control & $16(41)$ & $16(41)$ & $4(10.3)$ \\
\hline & & & Experiment & $13(35.1)$ & $20(54.1)$ & $4(10.8)$ \\
\hline & & \multirow[t]{2}{*}{ Follow Up } & Control & $2(12.8)$ & $24(61.6)$ & $10(25.6)$ \\
\hline & & & Experiment & $1(2.6)$ & $35(92.1)$ & $2(5.3)$ \\
\hline 6. & It is good to drink liquor with friends & Pre & Control & $1(2.6)$ & $33(84.6)$ & $5(12.8)$ \\
\hline & & & Experiment & $4(10.3)$ & $33(84.6)$ & $2(5.1)$ \\
\hline & & Post & Control & $9(23.1)$ & $25(64.1)$ & $2(5.1)$ \\
\hline & & & Experiment & $2(5.2)$ & $13(84.6)$ & $3(7.7)$ \\
\hline & & Follow Up & Control & $9(23.1)$ & $30(77)$ & - \\
\hline & & & Experiment & - & $38(100)$ & - \\
\hline
\end{tabular}

In table 2, it is indicated that, $92.4 \%$ of the respondents at pre intervention, in the control group disagreed with the statement which stated that parents should give liquor to students and
$79.5 \%$ of the respondents in the experimental group also disagreed with the statement. At immediate post intervention, $59 \%$ of the respondents in the control group disagreed with said statement while 
$100 \%$ of the respondents in the experimental group disagreed with the statement. At the follow up stage, $89.2 \%$ and $100 \%$ of the respondents in the control and experimental groups, respectively, disagreed with the statement. The mean score of the experimental group in both post intervention and during follow up session is higher than the mean score for the control group, suggesting that knowledge extended to the experimental group increased proper attitude of respondents against alcohol drinking.

With regard to whether parents should drink alcohol at home, the initial $84.6 \%$ of both the control and the experimental group disagreed, even though the percentage of those who disagreed with the statement after the intervention dropped to $58.9 \%$ and 63.9 respectively. But during the follow up time, only $89.2 \%$ of the control group disagreed while all respondents in the experimental group disagreed with the statement, meaning that knowledge extended to the experimental group increased proper attitude of respondents against alcohol drinking .

Regarding sending students to purchase alcoholic beverages for use by their teachers, $94.9 \%$ and $87.1 \%$ of the respondents in the control and in the experiment groups, respectively, disagreed. During the post intervention, the percentage of those who disagreed in the control group (76.9) dropped while the percentage of those who disagreed in the experimental group increased up to $100 \%$. Likewise, during the follow up session, $94.8 \%$ and $100 \%$ of the control and experimental groups, respectively, disagreed. This also supports the idea that knowledge extended to the experimental group increased proper attitude of against alcohol drinking but more so in the experimental group.

The idea of encouraging siblings in the home to consume alcoholic beverages was rejected by $82.1 \%$ and $84.7 \%$ in the control and experimental groups at pre intervention, respectively while after the intervention, $66.6 \%$ and $94.4 \%$ in the control and experimental groups, respectively, rejected the idea. But during the follow up session, the percentage of those who rejected the idea was $87.2 \%$ and $57.9 \%$ for the control and the experimental groups, respectively. The trends inform the reader that the positive change in attitude among the respondents in both groups was not stable, suggesting a need for continuous training and follow up sessions to boost the negative attitude toward alcoholic drinking among the respondents.

With regard to whether it is good to drink alcohol with friends, $84 \%$ of respondents in both the control and the experimental groups disagreed. It is worth noting that after the intervention process, the percentage of disagreement among the control and the experimental group members was 64.1 and 84.6 respectively and during the follow up session, the disagreement percentage of the control group was only 77 while for the experimental group was 100 . Therefore, the model used in the experimental group was more effective than the one used in the control group in inculcating appropriate attitude toward alcohol drinking.

Concerning whether students should bring alcoholic beverages to school, 71.7 and 53.3 of the control and experimental groups, respectively, rejected the idea while after intervention, rejection to the control group dropped to 41 while for the experimental group it increased to 54.1. During the follow up session, the rejection percentage for the control group was 61.6 while that of the experimental group was 92.1. In the same manner, $77 \%$ of the control group against $100 \%$ of the experimental group rejected that it is good to drink alcohol with friends. This suggests that while majority of respondents disagreed that it is right to drink alcohol with friends, the experimental group had gained more negative attitude toward alcohol drinking, suggesting that the intervention practice increases negative attitude toward drinking alcohol.

\section{Hypothesis Testing}

The null hypothesis which stated: there is no significant difference in mean scores on the reinforcing factors between the control and experimental groups in the post intervention and follow up session was guided by the second research question:

RQ2: Is there is a significant difference in mean scores on the reinforcing factors between the control and experimental groups in the post intervention and follow session?

Table 3 reveals the difference in the re-enforcing factor scores between the control and the experimental groups, where the critical value in the post intervention and the follow up sessions $(p=0.003$ and 0.000$)$ was lesser than the critical value, suggesting the difference is significant, leading to rejection of the null hypothesis. In both 
the post intervention and the follow up sessions, the mean score of the experimental group (11.7381, 13.9762) on the reinforcing factor is higher than that of the control group (10.7619 and 10.5238) which means the treatment extended to the experimental group significantly increased the mean score.

Table 3: Independent t-test for the re-enforcing factors between the control and the experimental groups

\begin{tabular}{llllllll}
\hline Session & Group & $\mathrm{N}$ & Mean & Std. Dev. & Df. & t-statistics & Sig. \\
\hline Pre-intervention & Control & 42 & 9.4524 & 3.351 & 82 & -2.119 & 0.037 \\
& Experiment & 42 & 11.5714 & 5.548 & & & \\
Post Intervention & Control & 42 & 10.7619 & 7.152 & 82 & -4.511 & 0.000 \\
& Experiment & 42 & 11.7381 & 4.793 & & & \\
Follow-up & Control & 42 & 10.5238 & 3.336 & 82 & -5.842 & 0.000 \\
& Experiment & 42 & 13.9762 & 1.880 & & & \\
\hline
\end{tabular}

Dependent variable: Re-enforcing factors

Since the prevalence rate of alcohol use of $50 \%$ among secondary school students in Liberia was reported as being higher than other countries in Africa such as Kenya, which had a prevalence rate of $5.2 \%$, the use of the alcohol and life skills training, which was employed to the experimental group, is more effective in increasing negative attitude toward alcohol drinking among high school students than the use of the HIV/ AIDS manual, which was employed to the control group. The findings are also supported by findings of a previous study conducted by Mohammed and Khaton (2017) and concluded that following an appropriate Model is an effective method in planning for and providing health education to improve knowledge, attitudes and behaviors regarding drug abuse and addiction among adolescent students and promoting reinforcing factors that support prevention of such problem.

\section{Conclusions and Recommendations}

This section presents conclusions and recommendations of the study, based on findings and discussions of the two research questions.

\section{Conclusions}

The study concludes that the use of the Alcohol and Life Skills Training Model is an effective educational tool to prepare students to make responsible decisions about abstaining from drinking alcoholic beverages. This is reflected in the fact that negative attitude toward alcoholic drinking was higher among students in the experimental group in which the model was used in training as compared to students in the control group where the HIV/ AIDS Model was employed in training.

\section{Recommendations}

Based on the conclusion above, the study recommends that the Government of Liberia should adopt the Alcohol and Life Skills Training Model into the National High School Curriculum in order to prevent and control the consumption of alcohol by students in high schools. Secondly, the researchers and the Ministry of Education in conjunction with other Ministries such as Health and Youth should conduct further research on a wider scale on alcohol consumption among the youth, including the inschool and the out of school adolescents in Liberia.

\section{Reference}

Alex-Hart, B. A., Opara, P. I., and Okagua, J. (2014). Prevalence of alcohol consumption among secondary school students in Port Harcourt, Southern Nigeria. https://www.ajol.inf >njp Alcohol Abuse and Crime in West Africa: What Prospect?

Armiya'u, A. Y. Drug Use and Crime in West Africa: what prospect? West Africa Insight,4(8), 1115. https://www.researchgate.net.

Bada, F. O. \& Adebiyi, D. R. (2014). Alcohol Consumption Behaviour among Secondary School Students in Nigeria. Journal of Educational and Social Research, 4(3) 507510. DOI: 10.5901/jesr.2014.v4n3p507

Chalder, M., Elgar, F. J., \& Bennett, P, (2006).

Drinking and Motivations to Drink Among Adolescent Children of Parents With Alcohol Problems. Alcohol \& Alcoholism https://academic.oup.com/alcalc/article/41 $/ 1 / 107 / 165427-$

Dumbili, E. W. Changing Patterns of Alcohol Consumption in Nigeria: An Exploration of Responsible factors and Consequences. 
(2013). A Journal of the BSA MedSoc Group $7(1), 20-33$.

Ferreira-Borges, C., Rehm, J., Dias, S., Babor, T., \& Parry, C. D. H. (2016). The impact of alcohol consumption on African people in 2012: an analysis of burden of disease. Tropical Medicine \& International Health (21)1, 5160. doi:10.1111/tmi.12618.

Harris, BL., Levey, EJ., Borba, PCP., Gray, DA., Carney, JR., \& Henderson, DC. (2011). Substance use behaviors of secondary school students in post-conflict Liberia: a pilot study, 190-201, https://doi.org/10.1080/17542863.2011.58 3737

Hoque, M., and Ghuman, S. (2012). Do Parents Still Matter Regarding Adolescents' Alcohol Drinking? Experience from South Africa (2012) Int. J. Environ. Res. Public Health, 9(1) 110-122; www.mdpi.com/journal/ijerph-

Hormenu T, Hagan Jnr JE, Schack T. (2018).

Predictors of alcohol consumption among in-school adolescents in the Central Region of Ghana: A baseline information for developing cognitive-behavioural interventions. PLoS ONE 13 (11): e0207093. https://doi.org/10.1371/journal. pone.0207093

Mohammed, RAR., and Khaton, SE.(2017). The Effect of an Educational Intervention Based on the PRECEDE- PROCEED Model on Knowledge, Behaviors and Attitudes of Adolescent Students Regarding Drug Abuse and Addiction 6, (4 )14-27.. IOSR Journal of Nursing and Health Science (IOSRJNHS) e-ISSN: 2320-1959.p- ISSN: 23201940 www.iosrjournals.org

Osei-Bonsu, E., Appiah, P.K., Norman, I.D, Asalu, G.A., Kweku, M., Ahiabor, S.Y., Takramah, W.K., Duut, A.B., Nwot, G.E., Boadu, S. (2017). Prevalence of Alcohol Consumption and Factors Influencing Alcohol Use Among the Youth in Tokorni-Hohoe, Volta Region,
Ghana. http://article.science publishing group.com/p df/10.11648.j. siph.201 70503.18.pdf-

Oshodi, O. Y. (2010). Substance use among secondary school students in an urban setting in Nigeria: Prevalence and associated factors. African Journal of Psychiatry 13(1), 52-72.

Pullen SJ, Petruzzi L, Lange BC, Parnarouskis L, Dominguez S, Harris B, Quiterio N, Durham MP, Lekpeh G, Manobah B, Slopadoe SP, Diandy VC, Payne AJ, Henderson DC, Borba CP.(2016). A Qualitative Analysis of Substance Use among Liberian Youth: Understanding Behaviors, Consequences, and Protective Factors Involving School Youth and the School Milieu. Int J Ment Health Psychiatry. 2(1).

Quiterio, N., Harris, B. L., Borba, C. P. C., \& Henderson, D C., (2013). Substance Use and Sexual Risk Behaviors Amongst in -School Youth and Young Adults Living in Liberia. African Journal of Drug \& Alcohol Studies, 12(2), 75-91. https://www.ajol.info.

Room, R. (2015). The history of psychoactive substance use and problems and of social responses to them. In: Haber, P., Day, C. \& Farrell, M., eds., Addiction Medicine: Principles and Practice, pp. 3-8. Melbourne: IP Communications. https://www .robinroom.net.

Singh, M., and Niwas, R. (2017) Attitude of Senior Secondary School Students towards Alcohol and Drugs With Respect To Gender, Residential Background And Type Of Family. Int. J. Adv. Res. 5(6), 529-535.

Verho, A., Laatikainen, T., Vartiainen, E., Puska, P. Changes in Alcohol Behaviour among Adolescents in North-West Russia between 1995 and 2004. (2012). https://www.ncbi.nlm.nih.gov.

WHO (2018) Global report on alcohol and health. https://www.wh 